\title{
Microstructure and biocompatibility of gold-lanthanum strips
}

\author{
Rebeka Rudolf • Sergej Tomić • Ivan Anžel • \\ Tjaša Zupančič Hartner • Miodrag Čolić
}

Published online: 16 August 2014

(C) The Author(s) 2014. This article is published with open access at SpringerLink.com

\begin{abstract}
Microalloying of pure gold, which has the highest biocompatibility but relatively low yield strength and poor wear resistance, might improve its applicability as adornments and biomedical implants. The objective of this study was to analyse the microstructure and biocompatibility of gold-lanthanum (Au- $0.5 \mathrm{wt} \% \mathrm{La})$ microstrips as a potential biomaterial in dentistry or medicine. We found that microalloying of $\mathrm{Au}$ with La produced very fine nanosized grains homogeneously dispersed through the entire volume of the rapidly solidified (RS) alloys. This initiates the formation of $\mathrm{Au}_{6} \mathrm{La}$ phase which increases strength and hardness of the alloy significantly. By RS, large reduction of grains and microsegregation increases the strength of the alloy additionally. Our results suggest that $\mathrm{Au}-\mathrm{La}$ microstrips, although non-cytotoxic for L929 cells, rat thymocytes, rat peritoneal macrophages (PMØ) and human peripheral blood mononuclear cells (PBMNCs), can activate immune cells. Namely, RS $\mathrm{Au}-\mathrm{La}$ microstrips stimulated the production of nitric oxide (NO) by PMØ. Using a model of phytohemaglutinine (PHA)stimulated human PBMNCs, we found that RS Au-La strips increased the proliferation of these cells and stimulated the
\end{abstract}

R. Rudolf $(\bowtie) \cdot$ I. Anžel

Faculty of Mechanical Engineering, University of Maribor, 2000 Maribor, Slovenia

e-mail: rebeka.rudolf@um.si

R. Rudolf

Zlatarna Celje d.d., Celje, Slovenia

S. Tomić · M. Čolić

Medical Faculty of the Military Medical Academy, University of

Defence, 11000 Belgrade, Serbia

\section{T. Z. Hartner}

Ortotip d.o.o., Murska Sobota, Slovenia

M. Čolić

Medical Faculty, University of Niš, 18000 Niš, Serbia production of Th1, Th17 cytokines, and immunoregulatory cytokine IL-10. Our results suggest that RS Au-La microstrips are biocompatible, but they can modulate the immune response. Therefore, their use as potential implants should be considered carefully.

Keywords Microalloying $\cdot$ Gold-Lanthanum $\cdot$ Rapid solidification · Biocompatibility $\cdot$ Immunomodulation

\section{Introduction}

Gold alloys are used in dentistry, not only for their preferred golden colour but also because they maintain an extremely high chemical stability in the mouth. They also possess several desirable mechanical properties, such as high strength, ductility and elasticity [1]. When considering the formulations of gold-based high noble alloys for porcelain bonding and other applications in dentistry, it is important to ensure all the required biomechanical properties, including not only their easy cast into thin sections but also their good biocompatibility. Pure gold, which has the highest biocompatibility, has relatively low yield strength and poor wear resistance, which limits its applicability in adornment and other biomedical applications. To improve these properties, the alloying elements such as silver, palladium, zinc and platinum are usually added [1, 2]. Dental alloys with high gold content were shown to have good biocompatibility due to the high corrosion resistance of gold. However, in vitro studies have demonstrated the release of alloying elements in culture media, artificial saliva or distilled water. Some of them could reach the levels that cause detectable cytotoxic effect $[2,3]$. Metal corrosion depends on an alloy's composition and microstructure, biomechanical conditions, mode of casting and polishing, composition and electrolyte characteristics of solutions used for 
alloy conditioning, size of the alloy's surface area exposed to solutions, duration of incubation time and other factors $[4,2]$.

The mechanical properties of pure gold can also be improved significantly by microalloying [5-7]. In recent years, significant effort has been made to increase the hardness of 24-carat gold alloys with a minimum of $99.5 \mathrm{wt} \%$ of $\mathrm{Au}$ [8], but such alloys exhibit only slightly higher hardness than pure gold in an annealed state. The usual alloying elements in microalloyed gold are used mainly as a grain refiner. In general, intensive work hardening can be achieved in the metals with decreasing grain size. However, in the finegrained alloys with low stacking fault energy, deformation with twinning can prevail as the main operative deformation mode. This decreases the effect of work hardening. Therefore, in gold, which is a metal with low stacking fault energy, no obvious strengthening can be expected by plastic deformation and grain size reduction. Therefore, it is necessary to introduce some other mechanisms of alloy strengthening, such as introduction of alloying elements, which are very different to gold in atomic radius and have lower density, or the use of elements with very low solubility in gold matrix. One such approach is the microalloying of gold with rare earth elements as suggested by theoretical analysis [5] and in our study we decided for lanthanum. Microalloying with lanthanum can serve as deoxidants to facilitate bonding between the alloy and the ceramic or to enhance the strength and colour of the alloy [9]. Consequently, lanthanum can improve the possibility to prepare thin strips by melt spinning. Therefore, $\mathrm{Au}-\mathrm{La}$ alloys, due to their specific characteristics, might be used as a potential biomaterial for various applications in medicine and dentistry. However, their biocompatibility and immunomodulatory properties are still unknown. Some studies suggested that lanthanum could be a toxic element [10], but little is known about its behaviour, corrosion stability and biocompatibility within gold-lanthanum alloy.

In this research, 24-carat gold was microalloyed with $0.5 \mathrm{wt} \% \mathrm{La}$, which usually have low solubility in gold. Our aim was to characterise Au-La alloy and then to investigate the alloy's biocompatibility using different in vitro models.

\section{Experimental}

Preparation and characterisation of gold-lanthanum strips and gold platelets

The investigated alloy Au- $0.5 \mathrm{wt} \% \mathrm{La}$ was made from pure gold $99.99 \mathrm{wt} \% \mathrm{Au}$ and pure lanthanum $99.9 \mathrm{wt} \% \mathrm{La}$. The alloy was prepared by melting and casting in an induction vacuum furnace at Zlatarna Celje under argon (Ar 5.0) inert atmosphere. The starting materials were then heated up to $1,200{ }^{\circ} \mathrm{C}$. Melting was performed in a crucible with ceramic insert. A ceramic insert made from $\mathrm{Al}_{2} \mathrm{O}_{3}$ with the addition of
$\mathrm{Cr}_{2} \mathrm{O}_{3}$ is suitable for casting precious metals and has high temperature resistance. From this graphite crucible, the melt was cast into a graphite mould with diameter $\varnothing 18-20 \mathrm{~mm}$.

Rapid solidification was performed by the chill-block melt spinning technique. The alloy was re-melted under an argon overpressure. The stream dropped on the wheel at a $90^{\circ}$ angle from a $1.7-\mathrm{mm}$-thick nozzle positioned $0.8 \mathrm{~mm}$ above the wheel rotating at $21 \mathrm{~m} / \mathrm{s}$. It was estimated that this speed is optimal for the selected alloy cast at $1,230^{\circ} \mathrm{C}$.

Continuous ribbons about $2 \mathrm{~mm}$ in width and $0.5-10 \mu \mathrm{m}$ in thickness were produced. The strips were cut into pieces $2 \mathrm{~mm} \times 4 \mathrm{~mm}$, cleaned ultrasonically and sterilised by $70 \%$ ethanol for $5 \mathrm{~min}$. Control gold platelets $(5 \mathrm{~mm} \times 5 \mathrm{~mm} \times$ $1 \mathrm{~mm}$ ) were polished and prepared by using the same procedure. The samples were then used for characterisation and biocompatibility and immunological studies.

The microstructural properties and differences between cast and rapidly solidified samples were generally observed with a light microscope (Nikon Epiphot 300). To accomplish more detailed information of the microstructure constituents and morphology, we used scanning electron microscopy by Sirion NC 400. Specimens for optical microscopy were obtained as vertical cross sections, prepared with standard metallographic methods and etched chemically in a mixture of 60 vol. $\% \mathrm{HCl}$ and 40 vol.\% $\mathrm{HNO}_{3}$ (for optical microscopy) and a solution of $\mathrm{CrO}_{2}$ in $\mathrm{HCl}$ (for electron microscopy).

Additionally, imaging with transmission electron microscope (TEM) Philips CM12 was performed on submicron particles inside the ribbons using the acceleration voltage $120 \mathrm{kV}$. Chemical composition was analysed by X-ray fluorescence (XRF). After the preparation of samples and their microstructural analysis, microhardness was measured by Zwick 3212 using a 50-g load.

\section{Cells}

The following cells were used as targets for biocompatibility and immunological studies: rat thymocytes; rat peritoneal macrophages (PMØ); L929 mouse fibroblasts; and human peripheral blood mononuclear cells (PBMNCs). Thymocytes were isolated from thymuses of 10-week-old, male, AO rats. The viability of the cells, as determined by $1 \%$ Trypan Blue staining, was higher than $95 \%$. РМØ were collected by aspiration of peritoneum of anaesthetised rats. The viability of peritoneal cells, of which $80 \%$ were macrophages, was higher than $95 \%$. L929, a mouse fibroblast cell line, was obtained from ATCC (Washington DC, USA). PBMNCs from eight healthy volunteers, who signed consent forms, were isolated from buffy coats by density centrifugation on Lymphoprep (Nycomed, Oslo, Norway). All studies on animal and human cells were approved by the ethics committee of the Military Medical Academy, Belgrade, Serbia. 
The cells were resuspended in RPMI 1640 medium supplemented with $10 \%$ foetal calf serum (FCS, Sigma) and 2mercaptoethanol (ME, Sigma), 2 mM L-glutamine (Sigma) and antibiotics (Galenika, Zemun, Serbia) including gentamycin $(10 \mu \mathrm{g} / \mathrm{ml})$, penicillin (100 units/ml) and streptomycin $(125 \mu \mathrm{g} / \mathrm{ml})$ (complete RPMI medium) and cultivated at $37{ }^{\circ} \mathrm{C}$ with $5 \% \mathrm{CO}_{2}$ for the indicated periods of time.

\section{Cytotoxicity assays}

The cytotoxicity of $\mathrm{Au}-\mathrm{La}$ strips or control gold platelets was tested using 3-[4,5-dimethylthiazol-2-lyl-2,5 diphenyl tetrazolium bromide (MTT) test, a standard method for the assessment of mitochondrial succinic dehydrogenase (SDH) activity. L929 cells $\left(5 \times 10^{4} / \mathrm{ml}\right)$, thymocytes $\left(5 \times 10^{6} / \mathrm{ml}\right)$, РMØ $\left(1 \times 10^{6} / \mathrm{ml}\right)$ and human PBMNCs $\left(2 \times 10^{5} / \mathrm{ml}\right)$ were cultivated with $\mathrm{Au}-\mathrm{La}$ strips or control Au platelets in flat-bottom 96-well plates (ICN, Costa Mesa, CA) $(250 \mu \mathrm{l} / \mathrm{well})$ in an incubator in complete RPMI medium for $24 \mathrm{~h}$ and 3 days. The surface area/volume of medium was $2.8 \mathrm{~cm}^{2} / \mathrm{ml}$. The cells cultivated without $\mathrm{Au}-\mathrm{La}$ strips, and Au platelets served as experimental controls.

After incubation of the cells for the indicated period of times, the medium was carefully removed and the wells were filled with $100 \mu \mathrm{l}$ of MTT (Sigma, Munich, Germany) (1 mg/ $\mathrm{mL}$ ), dissolved in the complete RPMI medium. The wells with $\mathrm{Au}-\mathrm{La}$ or Au platelets filled with $100 \mu \mathrm{l}$ of MTT, but without cells, served as controls. In addition, wells with $100 \mu$ of MTT solution served as blank controls. After a 3-h incubation period $\left(37{ }^{\circ} \mathrm{C}, 5 \% \mathrm{CO} 2\right), 100 \mu \mathrm{l} /$ well of $10 \%$ sodiumdodecyl sulphate (SDS)-0.1 N HCl (Serva, Heidelberg, Germany) was added to solubilise intracellularly stored formazan. The plates were incubated overnight at room temperature. The optical density of the colour was then measured at $570 \mathrm{~nm}$ in a spectrophotometer (Behring ELISA Processor II, Heidelberg, Germany). The results were expressed as the percentage of optical density (metabolic activity) compared to the control (cultures without $\mathrm{Au}-\mathrm{La}$ samples), used as $100 \%$ as follows: metabolic activity $(\%)=($ optical density (O.D.) of cells cultivated with $\mathrm{Au}-\mathrm{La}$ (or $\mathrm{Au}$ ) samples-O.D. of $\mathrm{Au}-\mathrm{La}$ (or $\mathrm{Au}$ ) samples without cells)/(O.D. of cells cultivated alone-O.D. of $\mathrm{Au}-\mathrm{La}$ (or $\mathrm{Au}$ ) samples cultivated alone) $\times 100$.

Cell death was determined by staining the cells from cultures with $1 \%$ Trypan Blue. The labelled cells, identified by light microscopy, were considered as dead, predominantly necrotic cells. The percentages of dead cells were determined on the basis of at least 500 total cells from one well. The percentage of viable cells was calculated as $100 \%$ of total cells $-\%$ of dead cells. All results were expressed as a mean of triplicates. Additionally, necrosis was confirmed using a staining protocol with propidium iodide (PI) (Sigma) without cell permeabilization by flow cytometry.

Apoptosis was assessed based on the detection of DNA fragmentation. For this purpose, the cultivated cells were collected and then washed with PBS, followed by incubation with PI $(10 \mu \mathrm{g} / \mathrm{ml})$ dissolved in a hypotonic solution $(0.1 \%$ sodium citrate $+0.1 \%$ Triton- $\mathrm{X}$ solution in distilled water). After incubation with PI, the cells were analysed by flow cytometry. L929 cells were detached from the plastic surface by using $0.25 \%$ trypsin (Serva, Heidelberg, Germany) before staining with PI.

For morphological evaluation of apoptosis, the cells were stained with Turk solution. The solution fixes and stains the nuclei, enabling a clear distinction between the chromatin structure in viable and apoptotic cells. At least 500 cells were examined in each sample, and the results are expressed as percentages of apoptotic cells. The detection of different stages of apoptosis and necrosis was analysed by flow cytometry using Annexin-V-fluorescein isothiocyanate (FITC)/PI staining kit (R\&D), following the manufacturer's protocol.

\section{Proliferation assays}

PBMNCs $\left(1.5 \times 10^{6} / \mathrm{ml}\right)$ were cultivated with Au-La strips or control Au platelets in flat-bottom 96-well plates (ICN, Costa Mesa, CA) $(200 \mu \mathrm{l} / \mathrm{well})$ in an incubator, using complete RPMI medium for 3 days. For stimulation of the cells, phytohemaglutinine (PHA, $30 \mu \mathrm{g} / \mathrm{ml}$ ) was added to cell cultures. During the last $18 \mathrm{~h}$ of incubation, the cells were pulsed with $1 \mu \mathrm{Ci} /$ well $[3 \mathrm{H}]$ thymidine $(6.7 \mathrm{Ci} / \mathrm{mmol}$, Amersham, Bucks, U.K.). Labelled cells were harvested onto glass fibre filters, and the incorporation of the radionuclide into DNA was further measured by $\beta$-scintillation counting (LKB-1219 Rackbeta, Finland). The results were expressed as counts per minute $(\mathrm{cpm}) \pm \mathrm{SD}$ of triplicates.

\section{NO and cytokine assays}

The effect of RS Au-La strips on production of nitric oxide (NO) by PMØ was assessed after 24-h cultures by measuring the nitrite levels using Griess reaction and calculating the unknown concentrations from the standard curve. The effect of $\mathrm{Au}-\mathrm{La}$ and $\mathrm{Au}$ platelets on cytokine production was studied using a model of PHA-stimulated PBMNCs. PHA-stimulated PBMNC cultures were incubated with $\mathrm{Au}-\mathrm{La}$ and $\mathrm{Au}$ samples for $48 \mathrm{~h}$, harvested and centrifuged, so the cell-free supernatants were collected and stored at $-20{ }^{\circ} \mathrm{C}$ for the subsequent determination of cytokine levels. The levels of cytokines in PHA-stimulated PBMNC culture supernatants were determined using FlowCytomix Human Th1/Th2 11plex Kit from Bender MedSystems (Vienna, Austria), to determine interleukin (IL)-1, IL-2, IL-4, IL-5, IL-6, IL-8, IL-10, IL-12, tumour necrosis factor (TNF)- $\alpha$, TNF- $\beta$ and interferon (IFN)- $\gamma$ levels. The levels of IL-17 in those cultures was determined using corresponding ELISA kits (R\&D Systems, Minneapolis, USA), following the manufacturer's instructions. 


\section{Statistical analysis}

All values are given as mean \pm standard deviation (SD). The number of samples was four to six. The Student $t$ test, paired $t$ test and ANOVA test were used for evaluating the differences between the experimental and corresponding control samples. The values $p<0.05$ or less were considered statistically significant.

\section{Results and discussion}

Preparation and characterisation of the $\mathrm{Au}-\mathrm{La}$ alloys

Upon preparation of conventionally solidified 24-carat gold microalloyed with $0.5 \mathrm{wt} \% \mathrm{La}$, which usually have low solubility in gold, we aimed to characterise the alloy. The phase diagram of $\mathrm{Au}-0.5 \mathrm{wt} \% \mathrm{La}$ [11], suggests that at the Au-rich corner, eutectic reaction occurs and results in two-phase microstructure with solid solution $\alpha \mathrm{Au}$ and eutectic $\left(\alpha \mathrm{Au}+\mathrm{Au}_{6} \mathrm{La}\right)$.

Next, we compared the microstructure of conventionally solidified $\mathrm{Au}-0.5 \mathrm{wt} \% \mathrm{La}$ alloy with pure Au (Fig. 1). Pure
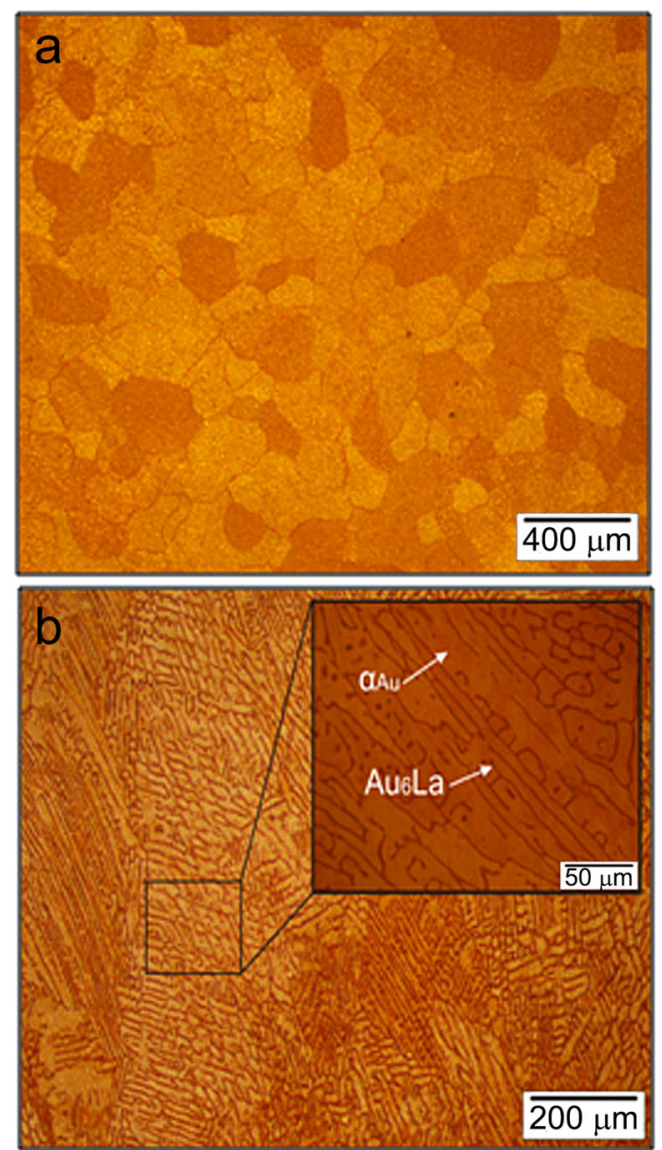

Fig. 1 Analysis of RS Au-La strips prepared by conventional solidification. Optical micrographs of a pure Au and $\mathbf{b} \mathrm{RS} \mathrm{Au}-\mathrm{La}$ strips, in as cast condition are shown. $\alpha \mathrm{Au}$ and $\mathrm{Au}_{6} \mathrm{La}$ phases are labelled by white arrows on the magnified inset
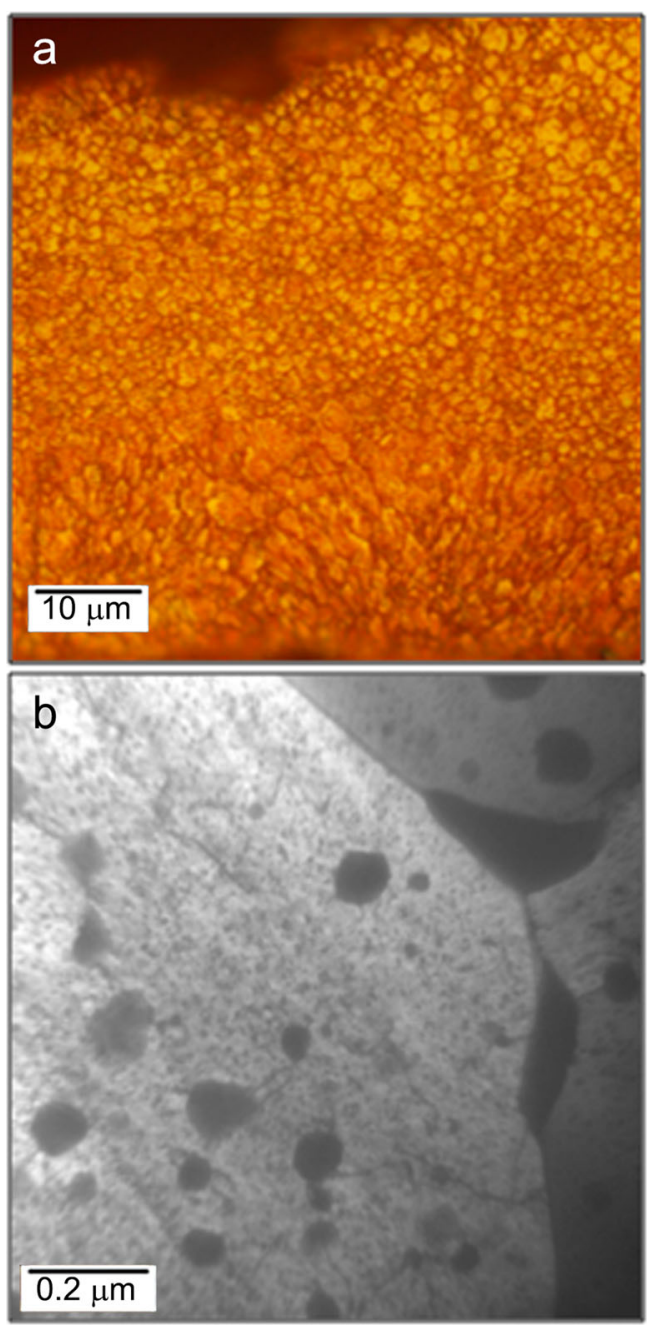

Fig. 2 Analysis of RS Au-La strips prepared by rapid solidification. Cross section of melt spun ribbon $\mathrm{Au}-\mathrm{La}$ was observed by a optical microscopy or b TEM

gold consists of equiaxed grains approximately $120 \mu \mathrm{m}$ in size. On the other hand, the microstructure of Au microalloyed by La consists of two phases. It contains mainly primary dendrites with some amount of eutectic phase in the interdendritic space. According to the phase diagram [11], the primary phase is a solid Au solution, and the eutectic is a combined $\alpha \mathrm{Au}$ and intermetallic phase $\mathrm{Au}_{6} \mathrm{La}$. Au dissolves an infinitively small quantity of $\mathrm{La}$, so the obtained solid solution in stable conditions is almost pure Au. As a result of the relatively fine distribution of eutectic, it can be predicted that the mechanical properties could be improved significantly compared to pure Au already in cast condition.

Rapid discharge of heat from the melt increases undercooling and, consequently, increases nucleation rate. As a result, grain refinement and metastable microstructure are achieved. Rapid solidification was performed by the chillblock melt spinning technique [3]. Figure 2a presents the microstructure of RS Au- 0.5 wt $\%$ La ribbons $0.5-10-\mu \mathrm{m}$ 
thick in transverse cross section. Figure $2 \mathrm{~b}$ suggests that the wheel side of the ribbons has a smooth surface and edge, and at the top side of the ribbons, the surface is wavy as a consequence of the streaming of argon gas above the melt in the travelling direction of the solidifying ribbons. The characteristic texture of the microstructure exhibits the direction of solidification. The wheel side of the ribbon, where solidification is initiated, is at the bottom. Close to this surface, a thin layer of fine equiaxed grains (outer equiaxed zone) is formed. These grains transit into columnar grains and, approximately at the centre of ribbon, into coarse equiaxed grains. The transition from the outer equiaxed zone to the columnar zone can be understood in terms of anisotropic growth effects [12, 13].

With rapid solidification, grain size was reduced to a few microns and less [13]. Because of unstable conditions during solidification and cooling, besides the reduction of grain size, an increased concentration of thermodynamically stable and unstable microstructure defects is present [14]. We can expect much higher concentrations of vacancies and substitution elements, in this case lanthanum; so the solid solution of gold could be oversaturated and, consequently, there should be smaller fraction of intermetallic phases [15]. With these unstable conditions, microsegregation on primary dendrites can be caused. In our case, coarser intermetallic particles appeared in the interdendritic space. Its degree is increased in the transition from columnar and equiaxed grains [16].

Rapid solidification in such a system can also have an effect on the fraction of eutectic and its phase composition [17]. If, in such condition, gold solutes over $0.5 \mathrm{wt} \%$ of $\mathrm{La}$ at eutectic temperature, eutectic reaction could be bypassed. Consequently, we could get a solid solution decorated only by coarser particles. Better interpretation of the formatted microstructure could be obtained by TEM electron images. Figure $2 b$ presents the microstructure of the rapidly solidified ribbons (coarse equiaxed zone), obtained with TEM. Coarser particles can be observed inside the grains and on grain boundaries. They are the result of microsegregation during rapid solidification. Inside the grains, small evenly dispersed particles also formed and the participations present nucleated from the oversaturated solid solution during cooling.

Finally, cast and melt spun samples were analysed individually to observe any possible deviations of chemical composition during heat treatment (re-melting). The data obtained from XRF analysis is presented in Table 1. One can see that there is a small loss of La after rapid solidification by melt spinning from the initial alloy, possibly because of La lost

Table 1 Chemical composition of $\mathrm{Au}-\mathrm{La}$ alloys obtained by XRF analysis

\begin{tabular}{lll}
\hline & $\mathrm{Wt} \% \mathrm{Au}$ & $\mathrm{Wt} \% \mathrm{La}$ \\
\hline Castings, $\mathrm{Au}-\mathrm{La}$ & 99.28 & 0.72 \\
Ribbons, $\mathrm{Au}-\mathrm{La}$ & 99.43 & 0.57 \\
\hline
\end{tabular}

during the manufacturing process (manipulation, more working phases, etc.) and because La oxidises more easily compared to $\mathrm{Au}$.

\section{Microhardness of $\mathrm{Au}-\mathrm{La}$ alloys}

Next, we investigated the mechanical properties of the obtained alloys by measuring microhardness. In Fig. 3, the microhardness of pure $\mathrm{Au}$, slowly solidified $\mathrm{Au}-\mathrm{La}$ and rapidly solidified $\mathrm{Au}-\mathrm{La}$ is presented. From these results, the high strengthening effect achieved by La and additional strengthening by rapid solidification can be determined as is predicted, besides a small loss of La during rapid solidification by melt spinning [17]. Pure Au has almost three times lower hardness in comparison to $\mathrm{Au}-0.5 \mathrm{wt} \% \mathrm{La}$, which reached up to $79 \mathrm{HV}$. This is due to participation of a hard secondary phase containing the intermetallic phase $\mathrm{Au}_{6} \mathrm{La}$. Rapid solidification of this alloy increased hardness further to a maximum value of approximately $99 \mathrm{HV}$.

More detailed research was made on rapidly solidified samples. Microhardness was measured in the columnar and coarse equiaxed grain zones. In the columnar zone, much higher microhardness was achieved than in the coarse zone. These results cannot give us exact values, only relative predictions, because of the very small thickness of the ribbons. Namely, if the smaller indentations were chosen, measurements would not give us the hardness of material but hardness of the phases. The microstructural gradient in the cross section of ribbon, which is due to the gradient of solidification rate, leads to the large differences in material hardness. In this case, the difference between hardness close to the free surface and hardness close to the wheel surface is almost $25 \%$.

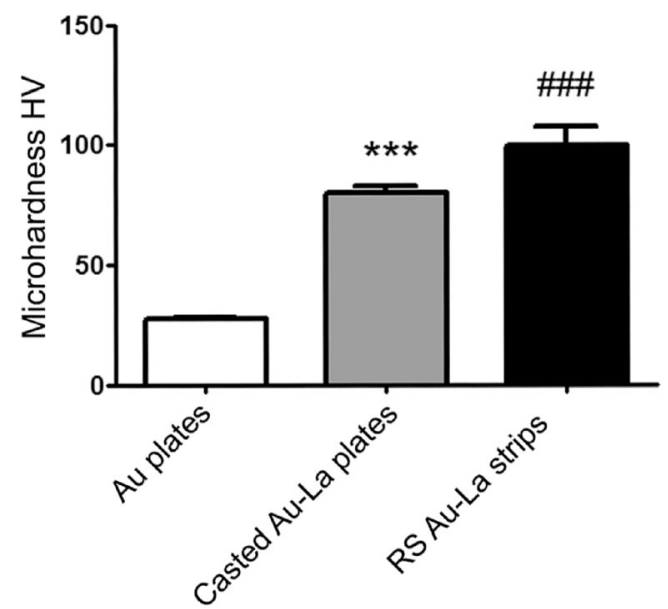

Fig. 3 Microhardness of Au-La alloys. Microhardness of Au-La alloys, prepared either by conventional solidification or rapid solidification, and microhardness of pure gold is shown. The results are presented as mean \pm SD of five measurements on different spots from a representative experiment, out of two with similar results. ${ }^{* * *} p<0.005$ compared to pure gold; \#\#\# $p<0.005$ compared to casted Au platelets (conventionally solidified) 
Cytotoxicity of RS Au-La strips in animal cell cultures

After showing that microalloying of Au with La could introduce better mechanical properties to the alloy, and that these could further be improved by rapid solidification, we wondered whether the RS Au-La alloys induce cytotoxicity in vitro. First, we tested the effect of RS Au-La strips on cytotoxicity of rat thymocytes, rat PMØ and L929 cells animal cells in vitro. These three different cell types were chosen for this part of study for the following reasons: L929 cells are the most commonly used targets for biocompatibility testing due to their sensitivity to the toxic effect of different materials and their soluble products and therefore are recommended by ISO standards as a screening cell target in biocompatibility studies [18]. Our previous original studies showed that rat thymocytes are more sensitive target for testing the biocompatibility of dental and implant materials than recommended L929 cells [4]. PMØ, a part of mononuclear phagocyte system, are recommended for biocompatibility studies of implant materials because the cells are the first ones responding to foreign materials by producing pro-inflammatory mediators [19]. By using viability and apoptosis assays, it has been shown that $\mathrm{Au}-0.5 \mathrm{wt} \% \mathrm{La}$ strips are not cytotoxic for the tested animal cells (Fig. 4a-c).

Lower viability of thymocytes and PMØ in both control wells and wells containing Au-La strips, compared to L929 cells, is a consequence of spontaneous cell death by apoptosis $[20,19]$, and such a finding was confirmed using apoptosis tests. Both morphological and flow cytometry methods showed that $\mathrm{Au}-\mathrm{La}$ strips did not cause apoptosis of the examined cells. Higher viability of L929 cells followed by very low rate of apoptosis could be explained by the fact that the cells are transformed (immortalised), showing high proliferative activity and low death process in vitro. Such results are encouraging for further studies because materials which cause cytotoxic effects in short-term culture are not advisable for insertion into human body as implants [21].

Effects of RS Au-La strips on NO production by peritoneal macrophages

Our previous study has suggested that gold-based material, although not cytotoxic, could induce functional response of immune cells $[22,23]$. To study the functional response of PMØ to Au-La strips, we have measured the production of NO, with or without additional stimulation by lipopolysaccharide (LPS), a known stimulator of TLR4-mediated activation of macrophages [24]. NO is an important molecule involved in different physiological and pathophysiological processes in the organism [25]. РMØ are an important source of NO, and the level of its production could serve as a sensitive parameter of PMØ activation [26]. The results presented in our study suggest that RS Au-La strips trigger the
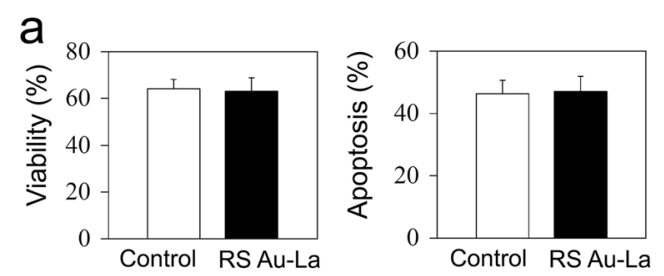

b
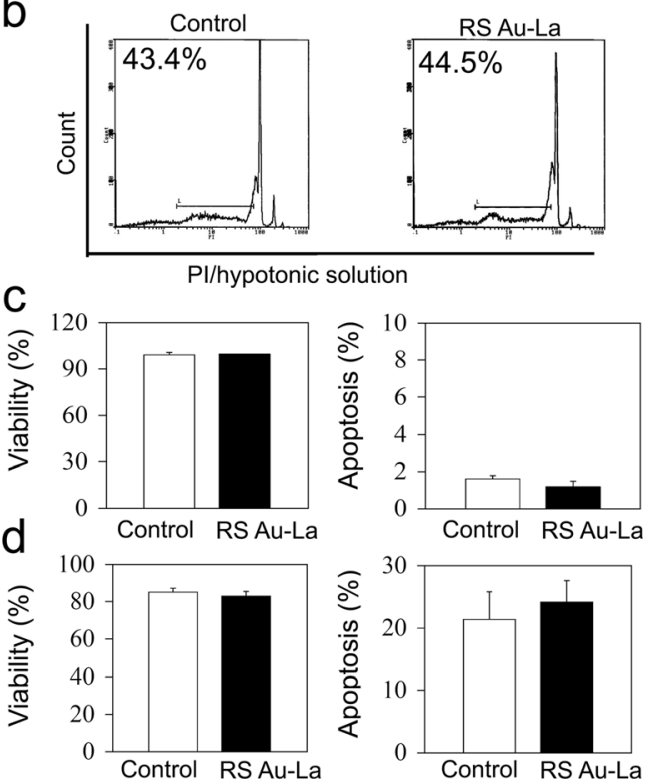

Fig. 4 Effect of RS Au-La strips on viability and apoptosis of animal cells in vitro. The effect of Au-La strips on viability and apoptosis of a rat thymocytes after 24-h cultures was analysed by MTT assay (viability) or staining of the cells with PI dissolved in hypotonic solution and Turk (apoptosis). The results are presented as mean $\pm \mathrm{SD}$ of three independent experiments, one of which is shown in (b). The effect of RS Au-La strips on viability and apoptosis of (c) L929 cell (d) rat PMØ after 24-h cultures is presented as mean $\pm \mathrm{SD}(n=3)$. Controls were cultures without $\mathrm{Au}-\mathrm{La}$ strips

production of NO by non-stimulated PMØ, whereas the material does not significantly modify the production of NO by LPS-stimulated PMØ (Fig. 5).

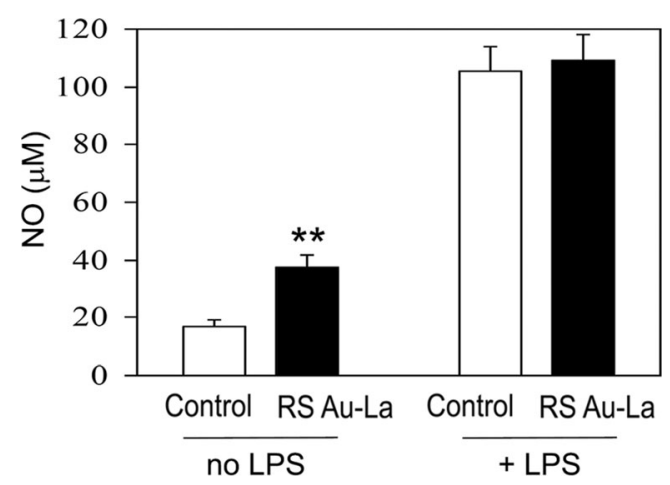

Fig. 5 Effect of Au-La strips on NO production by rat PMØ. PMØ (1× $\left.10^{6} / \mathrm{ml}\right)$ were stimulated with LPS $(100 \mathrm{ng} / \mathrm{ml})$ during $24-\mathrm{h}$ cultivation in the presence or absence of RS Au-La strips, after which the supernatant was collected and subjected to Griess reaction. ${ }^{* *} p<0.01$ compared to corresponding medium control 
These results suggest that $\mathrm{Au}-\mathrm{La}$ strips, although noncytotoxic for PMØ, are able to activate these cells. Lack of increased NO production by PMØ treated with both LPS and RS Au-La strips could be a consequence of its overstimulated production by LPS alone [27]. Alternatively, lanthanum may specifically interact with LPS signalling, disallowing further increase in NOS activity. In line with this, it was shown that $\mathrm{LaCl}_{3}$ inhibits LPS-induced production of NO by RAW264.7 macrophages [28], by inhibiting the induction of NF-KB expression upon stimulation [29, 30]. Additionally, it was shown that small concentrations of lanthanum can inhibit the production of active oxygen free radicals by PMØ at low concentration, but it turned out contrary at high concentration [31]. Lou et al. showed that $\mathrm{LaCl}_{3}$ $(2.5 \mu \mathrm{M})$ may somewhat increase the production of NO by macrophages in the absence of LPS [28], but the effect was not significant. The much stronger effect we observed in this study could be due to a specific action of Au-La surface, in addition to the effects of ionic or surface concentrated lanthanum. To evaluate this hypothesis, an additional control was included in the following study, namely, the pure gold platelets.

\section{Cytotoxicity of RS Au-La strips on human PBMNCs}

The response of animal and human cells can differ significantly [32], including the response to a biomaterial [33]. Therefore, the second part of biocompatibility study was designed to investigate the cytotoxic and immunomodulatory effect of RS Au-La strips on human PBMNCs isolated from eight healthy volunteers. As an additional control, platelets prepared from pure gold were used.

MTT assay and Annexin-FITC/PI assay showed that neither gold-lanthanum strips nor gold platelets induce cytotoxic effects on human PBMNCs (subpanels a and b of Fig. 6, respectively). Based on the previous results on animal cells and human cells, it can be concluded that $\mathrm{Au}-\mathrm{La}$ and pure $\mathrm{Au}$ do not induce acute cytotoxic effect. Since there are no cytotoxic effects in short-term culture, such materials are advisable for insertion into human body as implants. However, the response of the cells after prolonged exposure to $\mathrm{RS} \mathrm{Au}-\mathrm{La}$ strips remains to be evaluated before their safe biomedical application.

Immunomodulatory properties of RS Au-La strips in culture of stimulated PBMNCs

Even though the RS Au-La strips were not cytotoxic for rat PMØ, they caused the activation of these cells in culture without additional stimuli. Therefore, we aimed to investigate whether human PBMNCs could be functionally different when cultivated with RS Au-La strips.

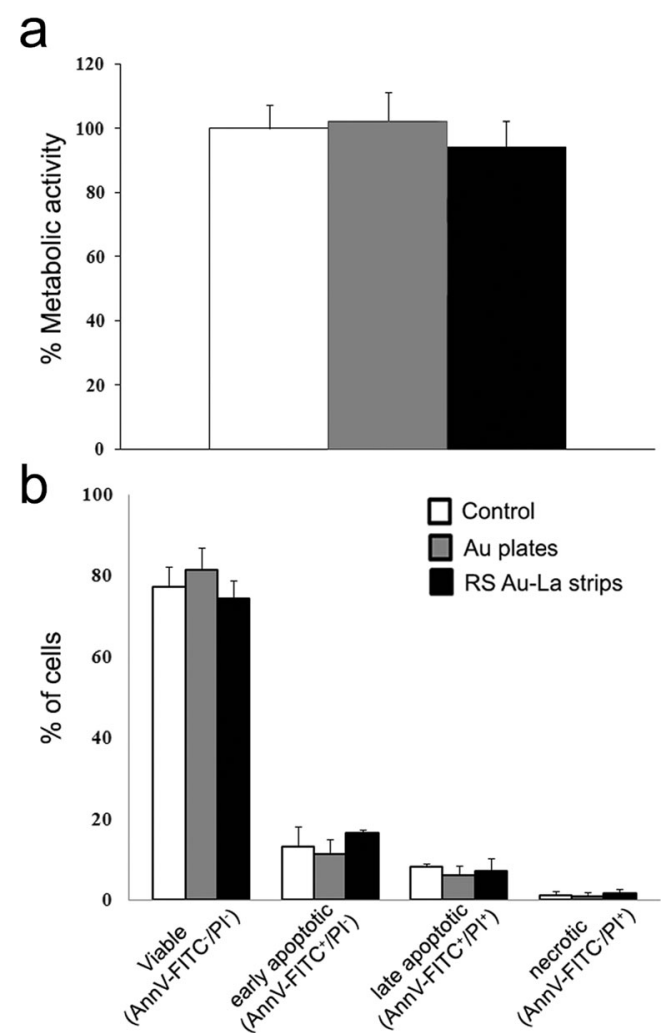

Fig. 6 Effect of RS Au-La strips on viability and apoptosis of human PBMNCs in vitro. PBMNCs were cultivated for $24 \mathrm{~h}$ in the presence or absence of pure $\mathrm{Au}$ platelets, $\mathrm{RS} \mathrm{Au}-\mathrm{La}$ strips or in medium (control). After the culture, a metabolic activity of the cells was determined by MTT assay or $\mathbf{b}$ Annexin V-FITC/PI staining. The results are shown as mean \pm $\mathrm{SD}$ of three independent experiments

The effect of $\mathrm{Au}-\mathrm{La}$ strips and Au platelets on proliferation of PHA-stimulated PBMNC is presented in Fig. 7a. The results suggest that $\mathrm{Au}-\mathrm{La}$ strips, in contrast to control $\mathrm{Au}$ platelets, stimulate proliferation of PHA-stimulated PBMNCs. This is a very interesting and unexpected finding which could be explained by the specific effect of La released from the surface of the strips or more probably by specific effect of $\mathrm{Au}-$ La surface compared to Au platelet surface. In line with the former hypothesis, it was shown that $\mathrm{LaCl}_{3}$ may promote proliferation and cytoskeleton reorganisation of rat osteoblasts via activation of focal adhesion kinase (FAK) [34] and increase proliferation of 3T3-L1 cells [35]. Interestingly, the same element can inhibit growth of cancer cells, by increasing the expression of p53, p16 and p21 [36]. It is unlikely that the possible release of contaminating metal ions from $\mathrm{Au}$ platelets or $\mathrm{Au}-\mathrm{La}$ strips is responsible for any of the observed biological effects. By using an inductively coupled plasma-atomic emission spectrometry (ICPAES) analysis, neither of the trace elements was detected in conditioning medium prepared from these samples (data not shown).

Previous results related to the proliferation of PBMNC are confirmed by analysing the cytokine profile in supernatants of 


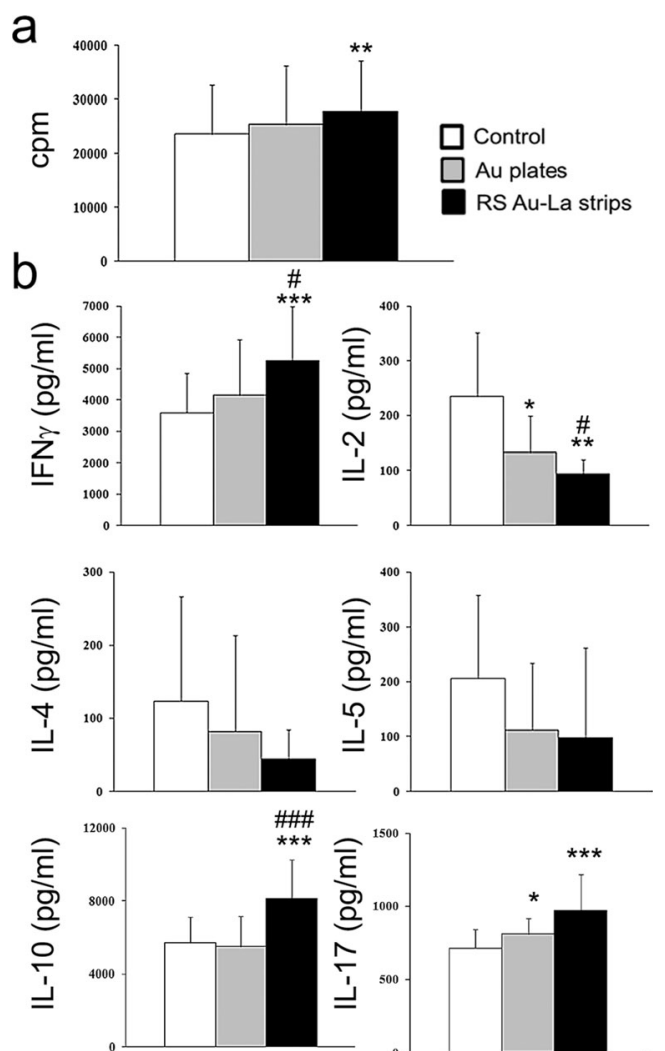

Fig. 7 Effect of $\mathrm{RS} \mathrm{Au-La} \mathrm{strips} \mathrm{on} \mathrm{the} \mathrm{proliferation} \mathrm{and} \mathrm{cytokine}$ production of human PBMNCs. The effect of RS Au-La strips on a proliferation of PHA-stimulated PBMNCs was determined after 3-day cultures by ${ }^{3}[\mathrm{H}]$ labelling of the cell cultures for the last $8 \mathrm{~h}$ and measuring the radioactivity on $\beta$-scintillation counter. The results are shown as mean count per minute $(\mathrm{cpm}) \pm \mathrm{SD}$ of three independent experiments, each carried out in 6-plicates. b The levels of IFN- $\gamma$, IL-2, IL-4, IL-5 and IL10 were determined from 3-day culture supernatants of PHA-stimulated PBMNCs using FlowCytomix Human Th1/Th2 11plex Kit or ELISA (IL-17). ${ }^{*} p<0.05,{ }^{* *} p<0.01,{ }^{* * *} p<0.005$ compared to control; ${ }^{\#} p<0.05$,

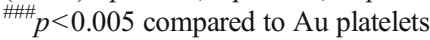

these cultures. Namely, we found significantly higher levels of INF- $\gamma$ in cultures with RS Au-La strips and lower levels of IL-2 (Fig. 7b).

IL-2 is a major proliferation-inducing factor of lymphocytes which they produce, and utilise via IL-2R, in an autocrine and paracrine manner [37]. Lower levels of IL-2 in culture supernatants could be a result of its increased utilisation by the proliferating cells. The levels of IL-2 were even lower in PBMNC cultures with control Au platelets, and this finding is also in accordance with slightly higher proliferative activity of these cultures compared to control PHAstimulated cells. IFN- $\gamma$ is the major cytokine produced by Th1 cells, suggesting that RS $\mathrm{Au}-\mathrm{La}$ strips promote Th1 differentiation of lymphocytes.

The levels of Th2 cytokines (IL-4 and IL-5) (Fig. 7b) in cultures with $\mathrm{Au}-\mathrm{La}$ strips or $\mathrm{Au}$ platelets were lower compared to corresponding controls, but due to significant individual variations between samples, the differences were not statistically significant. Lower levels of Th2 cytokines could be explained by the increased production of Th1 (IFN- $\gamma$ ) cytokines. The IFN- $\gamma$ enriched environment most probably caused the lower production of Th2 cytokines (IL-4 and IL-5) in the cultures, since it was shown that IFN- $\gamma$ through the transcription factor T-bet inhibits GATA-3-dependent differentiation and proliferation of Th2 cells [38]. It is interesting that $\mathrm{Au}-\mathrm{La}$ strips significantly increased the production of anti-inflammatory cytokine, IL-10, and a Th17 cytokine, IL17 (Fig. 7b). The production of IL-17 is also triggered by pure $\mathrm{Au}$. To our knowledge, such results have not been published yet, and without detailed timing of cytokine production and precise identification of their cellular sources, it is difficult to explain the physiological significance of this finding. IL-10, a key immunoregulatory cytokine, is produced by both antigen presenting cells (APCs) and T cells [39]. IL-17 is a key cytokine produced by a subset of memory T cells (Th17 cells) upon stimulation with IL-6 or IL- $1 \beta$ and TGF- $\beta$ [40]. At the moment, it is not clear why $\mathrm{Au}-\mathrm{La}$ strips trigger production of both Th1 (IFN- $\gamma$ ) and Th17 (IL-17) cytokines with proinflammatory properties, and IL-10, a cytokine with downmodulatory activity. It is possible that increased production of IL-10 is an important physiological feedback mechanism to control excessive $\mathrm{T}$ cell activation [41, 42]. In the context where lanthanum alone may exhibit anti-tumour effects [37], increased Th1/Th17 polarisation capacity of RS Au-La strips could be beneficial additionally for anti-tumour therapies, since such increased levels of Th1 and Th17 cytokines correlate with a good prognosis for tumour-bearing patients [43]. IFN- $\gamma$ production is stimulated predominantly by IL- 12 produced by APCs, and it induces a positive feedback loop for its own production [44]. Indeed, when measuring the levels of IL-12 in PHA-stimulated cultures, we found that RS Au-La strips statistically significantly increased the production of IL12 (Fig. 8) by PBMNCs. IL-12 is a key cytokine stimulating Th1 polarisation activity of T cells [44], and our finding that the level of IL-12 correlated with increased production of IFN- $\gamma$ supports this phenomenon. The levels of IL-12 in PBMNC cultures were relatively low because accessory cells, comprising up to $15 \%$ of total PBMNCs, are its main producers.

By further analysing cytokine production by PHAstimulated PBMNCs, we found that neither RS Au-La strips nor pure $\mathrm{Au}$ platelets modulate significantly the production of pro-inflammatory cytokines IL-6, IL- $1 \beta$, TNF- $\alpha$ and TNF- $\beta$ (Fig. 8). Unexpectedly, we observed that Au-La strips inhibit the production of IL-8. IL-8 plays different roles both in innate and specific immunity [45]. It is a main chemoattractant for recruitment of neutrophils to the inflammatory sites [46]. Therefore, lower production of this chemokine in the presence of $\mathrm{Au}-\mathrm{La}$, as a possible biomaterial, could be beneficial for down-regulation of non-specific inflammatory responses [45]. It is interesting that IL-17 cytokine production was increased 
Fig. 8 Effect of RS Au-La strips on cytokine production of human PBMNCs. The effect of RS $\mathrm{Au}-\mathrm{La}$ strips on the production of IL-12, IL-6, IL-8, IL-1 $\beta$, TNF- $\alpha$ and TNF- $\beta$ were determined from 3-day culture supernatants of PHA-stimulated PBMNCs using FlowCytomix Human Th1/Th2 11 plex Kit or ELISA (IL-17). ${ }^{*} p<0.05$ compared to control; ${ }^{\#} p<0.05$ compared to Au platelets
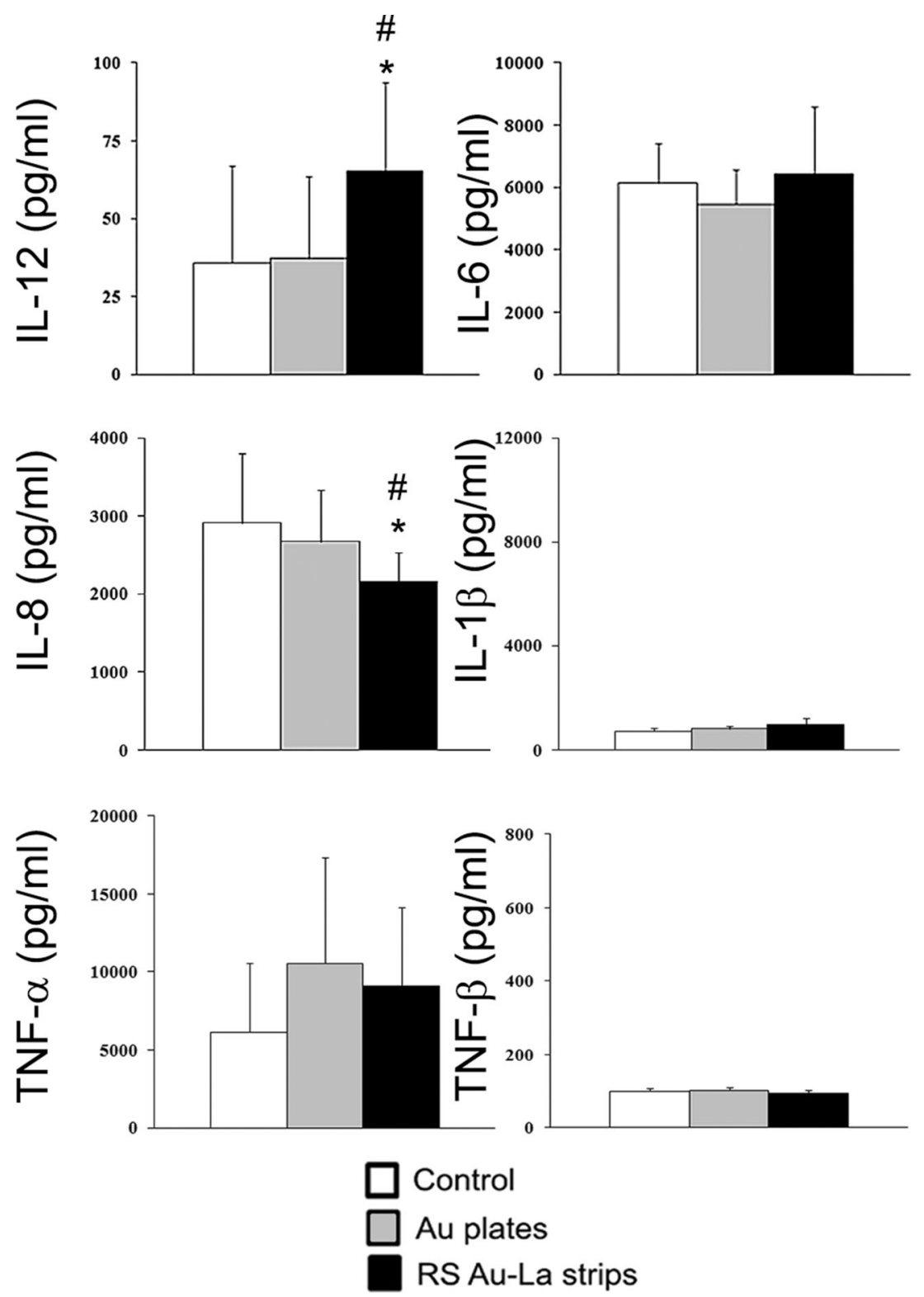

without the increase of IL- 6 or IL- $1 \beta$, which are important for its induction [39]. These findings suggest that other cytokines responsible for Th17 development, such as IL-23 [46], could be increased, which needs to be determined additionally.

Considering that the proliferation and cytokine production in the model of PHA-stimulated PBMNCs depends on presence of APCs within cell population, predominantly monocytes, it can be hypothesised that the effects of RS Au-La strips were mediated by functional modulation of APCs within PBMNC population. These results suggest that RS Au-La strips, although non-cytotoxic for animal cells (thymocytes, L929 cells and PMØ) and human PBMNCs, can activate them. We found an increased production of Th1 and Th17 cytokines along with increased production of IL-10, as a very important down-regulatory cytokine in PBMNC cultures stimulated with PHA [41, 42]. It seems that Au-La strips modulate predominantly adaptive immunity, mediated by $\mathrm{T}$ cells, without significant influence on the components of innate immunity, as judged by measuring the levels of pro-inflammatory cytokines produced by the cells of monocyte-macrophage system. However, it remains to be tested whether and how activation of APCs in our experimental system influences this arm of immunity. The dominant effect was observed on stimulation of Th1 and Th17 and down-regulation of Th2 responses. Since all these responses are mediated by APCs, it is important to further study not only the effect of $\mathrm{Au}-\mathrm{La}$ strips on Th polarisation capability of APCs but also on their immunophenotypic characteristics. 


\section{Conclusion}

The microalloying of $\mathrm{Au}$ by $\mathrm{La}$ initiates the formation of $\mathrm{Au}_{6} \mathrm{La}$ at a small alloying concentration. Such microalloying increases the strength and hardness significantly, caused by distribution of the primary phase between dendrites. Furthermore, with rapid solidification, a large reduction of grains and microsegregation increases the strength of the alloy additionally. Such mechanical properties could be outstanding for the preparation of biomedical constructs and prosthesis of various thicknesses. Since the alloy still contain $99.5 \mathrm{wt} \%$ of gold, it is expected to be tolerated well by the organism. Indeed, RS AuLa strips do not cause acute cytotoxicity in animal (L929 fibroblasts and rat PMØ) and human PBMNCs but can activate them. Therefore, care should be taken as to whether the ribbons will induce a desired or an adverse immunomodulatory effect in potential recipients. Namely, in conditions with the pathological Th17- or Th1-mediated inflammation, the implantation of RS Au-La strips could be adverse since they can exacerbate such conditions. On the other hand, in the Th2dominant immunopathology, implanted RS Au-La strips could inhibit the Th2 inflammatory process and induce tolerogenicity. To prove this hypothesis, extensive in vivo studies on different animal models should be conducted.

Acknowledgments This study was supported by the EUREKA Project E!3971 BIO-SMA and the Project of the Ministry of Science and Technological Development of Serbia (Project no. 175102). The authors thank the firm Zlatarna Celje d.d. and collaborators from the Military Medical Academy, Belgrade (T. Džopalić, A. Dragićević, J. Đokić, I. Rajković, S. Vasilijić) and Faculty of Mechanical Engineering, Maribor (I. Orožim) for their helpful assistance during the experiments.

Conflict of interest The other authors also declare no conflict of interest.

Open Access This article is distributed under the terms of the Creative Commons Attribution License which permits any use, distribution, and reproduction in any medium, provided the original author(s) and the source are credited.

\section{References}

1. Colic M, Stamenkovic D, Anzel I, Lojen G, Rudolf R (2009) The influence of the microstructure of high noble gold-platinum dental alloys on their corrosion and biocompatibility in vitro. Gold Bull 42: $34-47$

2. Geurtsen W (2002) Biocompatibility of dental casting alloys. Crit Rev Oral Biol Med 13:71-84

3. Tomić S, Rudolf R, Brunčko M, Anžel I, Savić V, Čolić M (2012) Response of monocyte-derived dendritic cells to rapidly solidified nickel-titanium ribbons with shape memory properties. Eur Cells Mater 23:58-81

4. Čolić M, Rudolf R, Stamenković D, Anžel I, Vučević D, Jenko M, Lazić V, Lojen G (2010) Relationship between microstructure, cytotoxicity and corrosion properties of a $\mathrm{Cu}-\mathrm{Al}-\mathrm{Ni}$ shape memory alloy. Acta Biomater 6:308-317
5. Corti CW (1999) Metallurgy of microalloyed 24 carat golds. Gold Bull 32(2):39-47

6. Corti CW (2001) Strong 24 carat golds: the metallurgy of microalloying. Gold Technol 33:27-36

7. Corti CW (2005) Microalloying of high carat gold, platinum and silver. Proceeding of the 2nd International Conference on Jewellerly Production Technology (JTF) Vicenza

8. Corti CW, Holliday RJ, Thompson DT (2002) Developing new industrial applications for gold: gold nanotechnology. Gold Bull 35: $111-117$

9. Shijie Z, Bingjun Z, Zhen Z, Xin J (2006) Application of lanthanum in high strength and high conductivity copper alloys. J Rare Earths 24:385-388

10. Palmer RJ, Butenhoff JL, Stevens JB (1987) Cytotoxicity of the rare earth metals cerium, lanthanum, and neodymium comparisons with cadmium in a pulmonary macrophage primary culture system. Environ Res 43:142-156

11. Okamoto H (2010) Phase diagrams for binary alloys. ASM International

12. Kurz W, Fisher D (1981) Dendrite growth at the limit of stability: tip radius and spacing. Acta Metall 29:11-20

13. Fisher D, Kurz W (1980) A theory of branching limited growth of irregular eutectics. Acta Metall 28:777-794

14. Honeycombe RWK (1975) The plastic deformation of metals. Edward Arnold, London W 1 Z 8 LL 1975, 477 p(Book)

15. Spaić S (1996) Fizikalna metalurgija I. Naravoslovnotehniška fakulteta, Oddelek za materiale in metalurgijo

16. Zupancic-Hartner T, Rudolf R, Kneissl AC, Anzel I (2009) Characterisation of the metastable microstructure of Au-La alloy. Prakt Met Sonderband 41:277

17. Ning Y (2005) Properties and applications of some gold alloys modified by rare earth additions. Gold Bull 38:3-8

18. International Standards Organisation (1997) Dentistry - preclinical evaluation of biocompatibility of medical devices used in dentistry - test methods for dental materials. ISO 7404, 1st edn. ISO, Geneva

19. Čolić M, Tomić S, Rudolf R, Anžel I, Lojen G (2010) The response of macrophages to a Cu-Al-Ni shape memory alloy. J Biomater Appl 25:269-286

20. Rinner I, Felsner P, Hofer D, Globerson A, Schauenstein K (1996) Characterization of the spontaneous apoptosis of rat thymocytes in vitro. Int Arch Allergy Immunol 111:230-237

21. Williams DF (2008) On the mechanisms of biocompatibility. Biomaterials 29:2941-2953

22. Đokić J, Rudolf R, Tomić S, Stopić S, Friedrich B, Budič B, Anžel I, Čolić M (2012) Immunomodulatory properties of nanoparticles obtained by ultrasonic spray pyrolysis from gold scrap. J Biomed Nanotechnol 8:528-538

23. Rudolf R, Friedrich B, Stopić S, Anžel I, Tomić S, Čolić M (2010) Cytotoxicity of gold nanoparticles prepared by ultrasonic spray pyrolysis. J Biomater Appl

24. Kawai T, Akira S (2010) The role of pattern-recognition receptors in innate immunity: update on Toll-like receptors. Nat Immunol 11: 373-384

25. Coleman JW (2001) Nitric oxide in immunity and inflammation. Int Immunopharmacol 1:1397-1406

26. Lorsbach RB, Murphy WJ, Lowenstein CJ, Snyder SH, Russell S (1993) Expression of the nitric oxide synthase gene in mouse macrophages activated for tumor cell killing. Molecular basis for the synergy between interferon-gamma and lipopolysaccharide. J Biol Chem 268:1908-1913

27. Bredt D, Snyder S (1994) Nitric oxide: a physiologic messenger molecule. Annu Rev Biochem 63:175-195

28. Lou Y, Guo F, Wang Y, Xie A, Liu Y, Li G (2007) Inhibitory effect of lanthanum chloride on the expression of inducible nitric oxide synthase in RAW264. 7 macrophages induced by lipopolysaccharide. 
Zhonghua shao shang za zhi $=$ Zhonghua shaoshang zazhi $=$ Chin $\mathrm{J}$ Burns 23:280-283

29. Guo F, He F, Xiu M, Lou Y, Xie A, Liu F, Li G (2013) Regulatory effects of lanthanum chloride on the activation of nuclear factor kappa B inhibitor kinase beta induced by tumor necrosis factor alpha. Zhonghua shao shang za zhi $=$ Zhonghua shaoshang zazhi $=$ Chin $\mathrm{J}$ Burns 29:531-536

30. Guo F, Guo X, Xie A, Lou YL, Wang Y (2011) The suppressive effects of lanthanum on the production of inflammatory mediators in mice challenged by LPS. Biol Trace Elem Res 142:693-703

31. Xue LH, Tao LX, Fen LJ, Chang LR, Kui W (2000) The effects of lanthanum, cerium, yttrium and terbium ions on respiratory burst of peritoneal macrophage $(\mathrm{M} \varphi)[\mathrm{J}]$. J Beijing Med Univ 3:003

32. Mestas J, Hughes CC (2004) Of mice and not men: differences between mouse and human immunology. J Immunol 172:2731-2738

33. Pearce A, Richards R, Milz S, Schneider E, Pearce S (2007) Animal models for implant biomaterial research in bone: a review. Eur Cell Mater 13:1-10

34. Wang X, Huang J, Zhang T, Wang K (2009) Cytoskeleton reorganization and FAK phosphorylation are involved in lanthanum (III)promoted proliferation and differentiation in rat osteoblasts. Prog Nat Sci 19:331-335

35. He M, Yang W, Hidari H, Rambeck W (2006) Effect of rare earth elements on proliferation and fatty acids accumulation of 3T3-L1 cells. Asian Australas J Anim Sci 19:119

36. Xiao B, Ji Y, Cui M (1997) Effects of lanthanum and cerium on malignant proliferation and expression of tumor-related gene. Zhonghua yu fang yi xue za zhi Chin J Prev Med 31:228-230
37. Malek TR (2008) The biology of interleukin-2. Annu Rev Immunol 26:453-479

38. Kaiko GE, Horvat JC, Beagley KW, Hansbro PM (2008) Immunological decision-making: how does the immune system decide to mount a helper T-cell response? Immunology 123:326-338

39. Steinman RM, Hawiger D, Nussenzweig MC (2003) Tolerogenic dendritic cells*. Annu Rev Immunol 21:685-711

40. McGeachy MJ, Cua DJ (2008) Th17 cell differentiation: the long and winding road. Immunity 28:445-453

41. Gabryšová L, Nicolson KS, Streeter HB, Verhagen J, Sabatos-Peyton CA, Morgan DJ, Wraith DC (2009) Negative feedback control of the autoimmune response through antigen-induced differentiation of IL10-secreting Th1 cells. J Exp Med 206:1755-1767

42. Meyaard L, Hovenkamp E, Otto SA, Miedema F (1996) IL-12induced IL-10 production by human T cells as a negative feedback for IL-12-induced immune responses. J Immunol 156:2776-2782

43. Qi W, Huang X, Wang J (2013) Correlation between Th17 cells and tumor microenvironment. Cell Immunol 285:18-22

44. Jouanguy E, Döffinger R, Dupuis S, Pallier A, Altare F, Casanova J-L (1999) IL-12 and IFN- $\gamma$ in host defense against mycobacteria and salmonella in mice and men. Curr Opin Immunol 11: 346-351

45. Harada A, Mukaida N, Matsushima K (1996) Interleukin 8 as a novel target for intervention therapy in acute inflammatory diseases. Mol Med Today 2:482-489

46. Lukić A, Vojvodic D, Majstorović I, Čolić M (2006) Production of interleukin-8 in vitro by mononuclear cells isolated from human periapical lesions. Oral Microbiol Immunol 21:296-300 